\title{
Vaginal Cæsarean Section, with Notes of Three Cases.*
}

\author{
By J. M. Munro Kerr, M.B., Ch.B., \\ Obstetric Physician, Glasgow Maternity Hospital, etc.
}

THE operation of Vaginal Cæsarean Section introduced to your notice to-night is one which so far has not aroused much attention in this country. Indeed I have recently come across quite a number of obstetricians who were entirely unaware of the meaning of the expression. In the English language I know of only one paper on the subject, that by Stamm in the November (1903) number of the American Journal of Obstetrics. In all probability the reason for this is that the metal dilators of Bossi and Frommer have so much engrossed attention that other methods of performing accouchement force have received but scant attention. Spealing generally, criticism has been adverse to the operation, although there are one or two outstanding obstetricians, such as Bumm, who have expressed themselves very strongly in its favour. While $I$ cannot agree with all Dührssen claims for the operation, and would certainly not perform it as extensively as he recommends, I do think it is an operation of great value in certain cases.

While saying so much in favour of Vaginal Cæsarean Section, I have no sympathy with the position Dührssen has taken up in some of his recent remarks in regard to metal dilators, for such instruments, even those most prejudiced against them will admit, are in certain cases of great value and usefulness. It is most unfortunate when one treatment is pitted against another, and in the case of metal dilators and vaginal Cæsarean section this is specially so, for each has its place.

Dührsen without doubt got his idea of this operation from the method of removing small submucous fibroids by splitting the cervix, which all of us have employed for some years. He first described the operation in 1895 in connection with accouchement forcé in eclampsia. In 1896 he published a monograph, entitled "Der vaginale Kaiserchnitt." Since then he has published other papers and made many communications on the subject to different societies. His latest remarks which $I$ have already taken exception to in so far as they condemn so decidedly the dilator of Bossi, appeared in the Archiv für Gynockologie, 1903, Bd. 69, Ht. 1, in which journal he

* Read at a Meeting of the Edinburgh Obstetrical Society, January 13th, 1904. 
and Bossi have been advocating their respective methods in most emphatic language. Others, especially Bumm, have written very appreciatively of the operation, and in the Epitome of the British Medical Journad for November 7th, 1903, a case by Saft is described. If search is made of the literature one can collect about 50 cases in all.

In a paper read before the Glasgow Obstetrical Society on November 23rd, 1903, introducing a discussion on accouchement forcé, I discussed each of the methods of performing the operation-manual dilatation, dilatation by rubber bags, dilatation with metal dilators (Bossi, Frommer) and incisions. Now, without trespassing on the subject of dilatation with Bossi's instrument which Dr. Ballantyne is going to bring up to-night, I may give you the conclusions come to regarding the instrument from the cases in which I have employed the dilator. (1) When the cervix is obliterated and the os will admit the finger without difficulty dilatation can be carried out in about 25 minutes, and there will be little or no laceration. (2) In cases where the pregnancy has advanced to term or nearly so, even although the cervix is not obliterated, dilatation may be accomplished with comparative safety to the cervix provided care, time and patience are expended on the operation. (3) In cases where pregnancy is not far advanced great caution must be exercised in using the instrument, and in spite of the greatest care there will often be lacerations.

Before going further, however, it must be clearly understood that Vaginal Cæsarean Section is a much more extensive operation than the deep incisions one makes to hasten delivery in cases of eclampsia, rigidity of the cervix, etc., where the cervix has become obliterated. Here are two examples of that treatment:- Some months ago I was asked by Dr. Grieve, Langside, to see a primipara, who had been twenty-four hours in labour. I found her with severe pains which were coming on every few minutes, and a rigid cervix which admitted one finger. The pulse and temperature were normal, and so I advised waiting, the administration of full doses of opium, hot douching, and if need be later, cocaine. This was done, but although she got some rest from the opium, little, if any, progress was made, so that after some forty hours Dr. Grieve again asked me to see her. By this time I found the os only a little more dilated, the pains still coming on severely, but the temperature fully $100^{\circ}$, and the pulse-rate about 110 . The child's heart sounds were also slower. I had no hesitation in saying that the uterus must be emptied. 'To accomplish this the choice lay between Bossi's 
dilator and deep incisions. I chose the deep incisions, which I made on each side right up to the vault of the vagina. I then ruptured the membranes, applied forceps and delivered the child without much difficulty and without lacerating the perineum. The operation took from 4-5 minutes; the child was asphyxiated, but soon recovered. The placenta was allowed time to separate and was then expressed by Crédé's method. The uterus was douched and the cervix stitched with catgut. The patient made a good recovery. Some months afterwards I examined the cervix and found it had healed almost perfectly. The second case occurred the other day; she was a primipara about term who had been sent into the Maternity Hospital on account of eclampsia. She was comatose, and had had many fits; her pulse was 140-150, small and irregular. The cervix was taken up, but the external os only admitted one finger. As the pulse was so unsatisfactory I decided to incise the cervix rather than dilate with Bossi's instrument, and I was glad I did so, for the child was saved when otherwise it would almost certainly have been lost. As before, the cervix was split on both sides right up to the vault, forceps were applied, and a live but very deeply asphyxiated child delivered. This was accomplished without perineal laceration in six minutes. After some time the child was resuscitated; it still lives. The placenta was removed, the uterus douched and the cervix stitched with great care. Before the patient left the hospital the cervix was examined, when it was found that the wounds had healed perfectly.

Vaginal Cæsarean Section is a very much more extensive operation, for it consists in separating the bladder from the anterior uterine wall, possibly the peritoneum from the posterior and splitting the cervix anteriorly, and if necessarily posteriorly, right into the uterine cavity. Not only that, but, if need be, the making of extensive vaginal incisions. The two cases which have been performed in Glasgow are as follows:-At the end of October a patient, a iii.-para, and about five months pregnant, was sent into the hospital on account of persistent vomiting. Every medicinal remedy had been tried. With absolute rest in bed and feeding by the bowel the sickness was arrested, but whenever one attempted to feed her by the mouth the sickness returned. One night my House Surgeon informed me that the patient had become very ill, and when I went along to the hospital I certainly found her so. She had been vomiting continuously for hours. Her pulse was about 160 and extremely feeble, and she certainly looked as if she had not long to live. I therefore determined to empty the uterus. 
After strychnine had been given, a mixture of ether and chloroform was administered. Repeatedly during the operation those in attendance could not feel her pulse. On examining vaginally I found that the cervix was completely closed and so rigid and firm that it would only admit a No. 10 Hegar. Do what I would I could not get in a larger size. Now, here I say there was absolutely no alternative in the way of treatment, for if $I$ had plugged or put in tents and waited for the os to dilate sufficiently the woman would have been dead. The only treatment was Vaginal Ccesarean Section. I separated the bladder well up as one does in vaginal hysterectomy, and it slips off the gravid uterus with the greatest ease. I then split the cervix right up beyond the os internum, and without any trouble scooped out the fretus and placenta. The whole operation took about four minutes. I then douched out the uterus, stitched up the wound, brought the bladder down again, and tacked it into its place, and finally put a loose piece of gauze into the vagina. The patient began to improve very shortly after the operation, and left the hospital in a most satisfactory state. She had no trouble with her bladder, and the wound healed perfectly, there being only a little dimple at the edge of the os externum. The second case which I will mention is one which my friend Dr. McLellan described at the last meeting of the Glasgow Obstetrical Society when we were discussing accouchement forcé, and he kindly said that I could refer to it to-night. The patient was a primipara, who after being 36 hours in labour was considered by Dr. McLellan to require prompt delivery. He incised the portio vaginalis, but finding that he did not obtain sufficient enlargement of the canal he stripped off the bladder and incised the cervix up the middle line. The child was extracted alive, and the stitching of the uterus afterwards was performed with the greatest ease. These two cases illustrate the ease of the operation and the fact that the after-stitching is not difficult.

The first and greatest argument in favour of Dührssen's operation is that sometimes it is the only method by which rapid emptying of the uterus is possible. Take for example case i., just described, where the cervix was so rigid that it would not stretch, or the case reported by Ehrendorfer (Zentralblatt für Gynäkologie, April 18th, 1903), also a case of uncontrollable vomiting in which the cervix could not be dilated. I am quite aware that such cases of extreme rigidity of the cervix are not common, and that they are very infrequent in the later months of pregnancy. Nevertheless every obstetrician of experience, and specially if he has a hospital 
practice, is liable to meet with them occasionally. If he refuses to adopt this method he has no alternative but to pack the cervix with gauze or some expanding tent and wait, and in some cases if he does that he will lose patients.

The second advantage is that the uterus can be emptied much more rapidly, for, roughly speaking, four or five minutes only are required. Here again the advantage is only occasionally of great importance. In most cases the difference between emptying the uterus in five minutes and in thirty minutes as with Bossi's dilator is immaterial. Still there are cases when the child's or mother's life or perhaps the lives of both may be saved by the more rapid method.

A third advantage claimed is the absence of shock. If a patient is deeply anæsthetised there generally is not much shock in forcibly dilating the cervix either with the hands or metal dilators. Sometimes, however, especially in heart cases and bad cases of eclampsia, even although the patient is apparently deeply under the anæsthetic, I have seen a degree of shock produced, although never in my experience so far has it been alarming. Personally, therefore, I cannot attach great importance to this claim.

The last advantage $I$ shall mention is that the operation is more surgical and that you have a clean cut to deal with. There is no doubt the operation is more surgical; it appeals to and satisfies the man of surgical instincts more than does forcible dilatation; you will therefore find it advocated most strongly by such men. That, however, does not of necessity make it the better operation, and it is a claim that should not be advanced for it proves nothing.

As regards the matter of having a clean cut to deal with, I think most of us will admit that when we have a cut to treat we prefer that it should be clean rather than lacerated, and if we knew that a cervix was going to lacerate with Bossi's dilator we would prefer incision; but we cannot tell that beforehand, and indeed, taking the recorded cases all over, there are not such a great number of lacerations recorded. But are there any cases where you may expect lacerations and where consequently you are better to incise than to dilate? I think there are.

In the British Medical Journal for January 9th is a short paper on accouchement forcé, more especially by means of Bossi's and Frommer's dilators, I emphasised the danger of forcibly dilating the cervix in cases of pregnancy of seven months or under. I have thrice seen extensive lacerations occur in such cases, twice in cases of my own. Many others have had a similar experience. In some cases also, they are not many I grant, one encounters great 
rigidity of the cervix even in the later months; such are the cases where you may expect lacerations and where incisions are better.

The most adverse criticism has come from those who have neither seen nor performed the operation, and in this particular matter I am not surprised, for the operation $a$ priori one would expect to be of considerable magnitude and difficulty, especially the after stitching. It is not so, however. The bladder can be pushed off the cervix with great ease, much more easily than in the non-gravid uterus. The incisions are not difficult to make if scissors are employed. The stitching is the most difficult part of the operation and requires good light and assistance. But if the edges are grasped firmly with volsellum forceps one can get the stitches introduced without much trouble, and the dragging on the uterus completely controls any hæmorrhage.

Allowing all that, one must, however, admit that it is an operation requiring some surgical experience, and is consequently not one suited for ordinary general practice. There Bossi's dilator, if it can at all with safety be employed, has its place. The other objection that at a subsequent pregnancy and labour there will be difficulty may or may not be true; so far no one can speak from experience; I should expect not, however.

If one looks over the literature of the subject one finds that malignant disease of the gravid uterus, eclampsia, heart disease, accidental hæmorrhage, persistent vomiting have been the chief indications. Now it is a little difficult and perhaps not wise to predict the place Vaginal Cæsarean Section will occupy in the future. That it has come to stay I am certain. It will usually be the operation of choice in cases where the cervix is too rigid to dilate and where the uterus must be emptied at once, in cases where every moment is of value in emptying the uterus, and in cases where there is a likelihood of laceration occurring if metal dilators are employed. Perhaps, and here I think I am on safe ground, its great place will be in accidental hamorrhage in which so many recommend hysterectomy. As regards the operation in eclampsia, it should displace ordinary Cæsarean section in the rare cases of unobliterated and rigid cervix; Bossi's dilator, however, will serve for most cases.

Since the foregoing paper was written I performed the operation (Feb. 13) in a case of eclampsia with a result by no means very good. The patient, a primipara, about eight months pregnant, was admitted to the Glasgow Maternity Hospital with a history from her doctor 
that she was having eclamptic seizures every few minutes, and that to his knowledge she had had between twenty and thirty fits. She had three in the ambulance waggon and five while being washed and prepared for operation. There was hardly any interval between them and they were very severe. Her condition was critical, as her pulse was becoming more rapid, feebler and intermittent. I decided to empty the uterus by accouchement forcé and chose Vaginal Cæsarean Section, because the cervix was not in the slightest degree taken up and was so rigid. The operation was extremely difficult, for the canal was very narrow and œdematous. To add to the difficulty the cervix could not be pulled down as the uterus caught on the brim, which was slightly contracted. I separated the bladder, incised the cervix, and extracted the child with forceps. It was dead. There was hardly any bleeding after delivery and the uterus was tonically contracted so that the cervix could still not be pulled down, and it was with great difficulty I stitched the cut edges of the cervical wound. Passing a catheter into the bladder I was sorry to find there was a small laceration about its neck. How it had occurred I cannot say, it was so low down that I can hardly think I did it with the seissors. Nore probably it was produced in dragging the head through the undilated passage. The patient made a most excellent recovery. After delivery she had four fits, but at long intervals. She is to-day (February 17th) quite sensible and passing large quantities of urine partly by the vagina, but chiefly through the winged catheter which is fixed into the bladder. 